\title{
Estudo do mercado da carne bovina proveniente de uma aliança mercadológica
}

\author{
Maysonnave, G.S. '; Pascoal, L.L. ${ }^{1}$; Vaz, F.N. ${ }^{1}$; Genro, T.C.M. ${ }^{2}$; Pinho, A.P.S. ${ }^{3}$, Pacheco, P.S. ${ }^{\text {; }}$, Severo, M.M. ${ }^{1}$ e Rodrigues, \\ A.C.T. ${ }^{1}$
}

'Departamento de Zootecnia da Universidade Federal de Santa Maria. Santa Maria. RS. Brasil.

${ }^{2}$ Empresa Brasileira de Pesquisa Agropecuária. Centro de Pesquisa de Pecuária dos Campos Sul-Brasileiros. Bagé. RS. Brasil.

${ }^{3}$ Universidade Federal do Pampa. Campus Dom Pedrito. São Geraldo. Dom Pedrito. RS. Brasil.

\section{PALAVRAS CHAVES ADICIONAIS}

Cadeia de produção.

Diversificação de produtos.

Indicações de procedência.
Agregação de valor.

\section{RESUMO}

O trabalho teve como objetivo caracterizar a cadeia produtiva de carne bovina da marca APROCCIMA, bem como identificar as percepções de qualidade na cadeia de produção e o comportamento do consumidor com relação ao produto. Essa marca de carne está organizada para trabalhar na forma de aliança mercadológica com certificação de origem. O método de pesquisa envolveu três momentos distintos: 1 - por meio de entrevista aos coordenadores da aliança, foram identificados os quatro agentes envolvidos na cadeia de produção: produtores, agroindústria de processamento, varejistas e mercado consumidor; 2 - aplicação de questionários estruturados aos três primeiros elos, com perguntas comuns que visaram identificar as percepções entre esses agentes; 3 - teste de aceitabilidade dos consumidores, feito por meio de amostras de carne distribuídas aos potenciais consumidores desses produtos, diretamente nos pontos identificados. A cadeia de produção está caracterizada por treze produtores, uma agroindústria e quatro mercados varejistas que comercializam em duas cidades. A carne bovina APROCCIMA, teve aceitabilidade em relação ao produto no julgamento de potenciais consumidores, apontando possíveis mercados futuros para o produto cárneo da aliança mercadológica.

\section{Beef market study from an alliance of merchantability}

\section{SUMMARY}

\section{ADDITIONAL KEYWORDS \\ Added value. \\ Origin indications. \\ Production chain. \\ Product diversification.}

INFORMATION

Cronología del artículo.

Recibido/Received: 16.10.2016

Aceptado/Accepted: 22.02 .2018

On-line: 15.04 .2018

Correspondencia a los autores/Contact e-mail:

fabianonunesvaz@gmail.com

\section{INTRODUÇÃO}

As constantes e profundas transformações que caracterizam as sociedades modernas têm gerado novas tendências de mercado, afetando o perfil de consumidor de carnes e o seu padrão de consumo (Regmi; Gehlthar, 2001). Neste cenário, estar atento às novas exigências do mercado é imprescindível e requer uma maior compreensão e conhecimento sobre a organização e funcionamento das alianças mercadológicas
(Malafaia et al., 2010). No âmbito das cadeias agroindustriais, a coordenação da mesma é um ponto-chave para o desenvolvimento e acesso a novos mercados (Ferreira e Padula, 1998).

De acordo com Neumann e Barcellos (2006), na cadeia produtiva da carne bovina, embora haja uma dependência natural entre os elos, não existe uma relação de comprometimento efetiva entre os mesmos. Segundo os autores, não há uma estrutura de coordenação suficientemente capaz de elaborar um planejamento 
global para a cadeia, definir as funções e organizar as negociações entre os diferentes agentes. Embora venha se aperfeiçoando com o passar dos anos, ainda se caracteriza por possuir uma estrutura ultrapassada, desprovida de coordenação, onde os elos trabalham de maneira individualizada buscando atender as expectativas próprias (MALAFAIA et al., 2010).

As alianças mercadológicas surgem em contraponto a essa situação. Visam estabelecer novas relações entre seus elos, substituindo a relação conflituosa tradicionalmente existente por uma relação de cooperação. Segundo Neumann e Barcellos (2006), as alianças propõem novas formas de coordenação da cadeia produtiva, através do estabelecimento de parcerias entre seus agentes, com o objetivo de ampliar sua competitividade.

Segundo Pineda e Rocha (2002), além de sintonia entre os elos as alianças mercadológicas objetivam transformar a carne de um produto "commodity" em produto diferenciado no mercado, reconhecido pela sua marca e especificações técnicas, agregando valor ao produto final. A agregação de valor está baseada na diferenciação do produto, inovação e competitividade no mercado. Todas as formas de agregação objetivam um retorno adicional, e deveriam buscar atender as necessidades e expectativas dos consumidores (Batalha, 2009).

O entendimento das alianças mercadológicas hoje estabelecidas na cadeia produtiva da carne bovina de qualidade ultrapassa a noção da transação de compra e venda, constituindo um compromisso estratégico de negociação assumido entre os segmentos de produção (pecuaristas), de processamento (frigorífico) e de distribuição (supermercados e açougues) de carne bovina de qualidade (Lima e Anjos, 2017).

O estudo das alianças mercadológicas, na medida em que se propõe a estabelecer mecanismos de coordenação para a cadeia da pecuária de corte e possui o foco na produção de carne de qualidade, pode representar uma importante ferramenta para auxiliar produtores a qualificar seu produto e viabilizar sua venda.

O projeto teve como objetivo caracterizar a cadeia produtiva de carne bovina da marca APROCCIMA (Associação de Produtores Rurais dos Campos de Cima da Serra), que se organiza na forma de aliança mercadológica, bem como identificar a percepção de qualidade na cadeia de produção e o comportamento de potenciais consumidores com relação ao produto.

\section{MATERIAL E MÉTODOS}

O presente trabalho realizou-se por meio de uma pesquisa de natureza exploratória descritiva com os diferentes agentes integrantes da cadeia produtiva de carne bovina APROCCIMA. De acordo com Malhotra (2006), a pesquisa descritiva tem como principal objetivo a descrição de algo, normalmente características ou funções do mercado.

O método de pesquisa envolveu três momentos distintos:
1 - Identificação dos agentes e caracterização da estrutura e funcionamento da aliança mercadológica;

2 - Caracterização dos elos de produção, industrialização e distribuição;

3 - Aceitação do consumidor pelas carnes bovinas com a marca APROCCIMA.

A identificação objetiva da cadeia produtiva foi feita primeiramente através de estudos prévios e informações disponíveis em fontes secundárias, para elaboração do pré-diagnóstico que permitiu elencar os atores-chave da mesma (Wood Junior e Zuffo, 1997).

Por meio de entrevista aos participantes da aliança, foram identificados os quatro agentes envolvidos na cadeia de produção: produtores (13), agroindústria de processamento (1), varejistas (4) e mercado consumidor. Estes foram elencados de montante a jusante, a partir dos sistemas de produção da região dos Campos de Cima da Serra (Rio Grande do Sul, Brasil).

Após ser traçado um roteiro, ordenado pelos elos de forma agrupada foram procedidas as entrevistas diretas e aplicação dos questionários com os respectivos atores-chave, nas regiões significativamente mais expressivas. Desta forma se obteve a caracterização da cadeia produtiva através da identificação dos seus elos e a compreensão da sua estrutura e funcionamento.

O instrumento de coleta de dados é o documento por meio do qual as questões foram apresentadas aos respondentes e onde foram registradas as respostas e os dados obtidos. Nesta pesquisa foi adotado o modelo de questionários estruturados, constituídos de questões abertas e fechadas, específicos para cada elo da cadeia de produção. As questões fechadas fornecem, ao entrevistado, certo número de opções para que assinale uma ou mais. As questões abertas não restringem a resposta do entrevistado. Ambas podem compor o mesmo questionário, depende do objetivo do estudo (Vieira e Hossne, 2015).

\section{a) Produção, industrialização e distribuição}

A primeira etapa da coleta dos dados foi realizada através de entrevista e da aplicação de questionários estruturados aos três primeiros elos, com perguntas comuns que visaram identificar as percepções de qualidade entre esses agentes.

\section{b) Consumidores}

A segunda etapa da coleta de dados deu-se por meio de duas fases: 1) aplicação de questionário ao elo consumidor: elaborado com linguagem acessível ao público, buscando a caracterização do perfil; 2) teste de aceitação: para analisar o comportamento dos consumidores em relação ao produto cárneo da marca APROCCIMA.

Para avaliação da aceitação, a pesquisa contou com a etapa que consistiu no teste de aceitabilidade, feito por meio de amostras de carne distribuídas aos potenciais consumidores desses produtos, diretamente nos pontos identificados na análise da cadeia de produção.

Foram apontados o número de consumidores e as cidades nas quais os produtos deveriam ser direcio- 
nados e assim, possivelmente desenvolver estratégias futuras para possíveis mercados. A análise sensorial enfocou nas características sensoriais do produto na intenção de se determinar o grau de aceitação do público-alvo pelo produto oferecido.

Os consumidores foram selecionados de acordo com uma amostragem representativa da população (cidade). A análise sensorial e os testes de aceitação da carne foram realizados na cidade de Santa MariaRS, durante a $48^{\mathrm{a}}$ Expofeira Agropecuária, no mês de outubro de 2015. Contou-se com a participação de 114 pessoas. As amostras de carne foram descongeladas, assadas em churrasqueira a gás, até alcançarem a temperatura interna de $70^{\circ} \mathrm{C}$, cortadas em cubos e oferecidas embaladas em papel alumínio aos participantes.

O teste foi realizado em uma única etapa onde cada consumidor recebeu uma amostra da carne bovina APROCCIMA e após a degustação eram convidados a responder um questionário composto por três questões onde puderam avaliar através de uma escala hedônica o quanto gostaram ou desgostaram do produto que provaram.

A escala utilizada para aceitação dos produtos foi de 1 a 5, a qual determinou o nível de satisfação, onde o valor $1=$ desgostei muitíssimo e valor $5=$ gostei muitíssimo. Além disso, os consumidores foram questionados quanto à intenção de compra para qual foi utilizada uma escala estruturada verbal de 5 pontos, variando de "certamente compraria" a "certamente não compraria" (Minim, 2012). As categorias da escala hedônica atribuídas pelos consumidores a cada amostra foram posteriormente convertidas a valores numéricos para análise estatística descritiva.

Após a coleta dos dados, estes foram analisados utilizando o software Microsoft Office Excel 2007 ${ }^{\circledR}$, calculando-se o número de respostas, médias, frequência e coeficiente de variação para cada questão.

\section{RESULTADOS E DISCUSSÃO}

\section{PRODUÇÃO}

No intuito de se caracterizar o elo da produção animal foi elaborado um questionário que abrangeu três tópicos principais: produção, comercialização e consolidação do mercado. $\mathrm{O}$ mesmo foi subdividido da seguinte maneira: produção (caracterização do produtor e caracterização da unidade de produção), comercialização (caracterização da comercialização de bovinos) e consolidação do mercado (ingresso em outros mercados, consolidação nos mercados já conquistados, aumento das vendas nos mercados já conquistados).

A amostra de produtores contou com um número de 13 entrevistas, sendo representados quanto ao gênero por 11 homens (85\%) e 2 mulheres (15\%).Vale salientar que o número de produtores total da aliança em estudo era de 14 produtores, sendo que destes, 13 foram entrevistados (94\%) o que torna bastante representativa a amostra para caracterização do elo em questão.

A idade média é de 57 anos. Quanto à escolaridade, o grau de instrução com maior prevalência é o ensino superior, representando $85 \%$ do total (Tabela I). As unidades de produção se concentram nas cidades de Campestre da Serra, Vacaria, André da Rocha, São Francisco de Paula e Bom Jesus.

Observa-se que o tempo na atividade dos produtores da aliança gira em torno de 31 anos, sendo que o tempo mínimo é de 4 e o máximo de 50 anos e contam com o a média de duas pessoas da família envolvidas (Tabela I).

As unidades de produção pertencentes à aliança mercadológica APROCCIMA, se caracterizam pela heterogeneidade de tamanho entre elas, apresentando propriedades que vão de menos de 100 a mais de 5.000 ha de área total.

Na Tabela II estão expostas informações referentes à área total e pastoril e rebanho referente aos anos de 2012 a 2014. A média encontrada é de 1.286 ha e 430 ha para área pastoril. Os desvios padrão encontrados são de \pm 1.339 e \pm 392 , respectivamente. Vale salientar, que os altos valores de desvio padrão podem ser explicados pela discrepância de tamanho entre as propriedades que apresentaram máxima de 5.517 ha e mínima de 86 ha de área total e máxima de 2.300 ha e mínima de 23,3 ha de área pastoril.

Nota-se que quando se trata do número de cabeças do rebanho, os anos de 2012, 2013 e 2014 apresentaram médias muito próximas, 852, 793 e 855, respectivamente. Este resultado indica que não houve aumento signi-

\begin{tabular}{|c|c|c|c|c|}
\hline Característica & & Número & Desvio-padrão & Percentual \\
\hline \multirow[t]{2}{*}{ Gênero } & Masculino & 11 & & $85 \%$ \\
\hline & Feminino & 2 & & $15 \%$ \\
\hline Idade & Média & 57 & $\pm 5,95$ & \\
\hline Grau de & Ensino médio & 2 & & $15 \%$ \\
\hline Escolaridade & Ensino superior & 11 & & $85 \%$ \\
\hline \multirow[t]{3}{*}{ Tempo na atividade } & Média (anos) & 31 & \pm 11 & \\
\hline & Mínimo & 4 & & \\
\hline & Máximo & 50 & & \\
\hline Pessoas da família envolvidas na atividade & Média & 2 & & $\pm 0,84$ \\
\hline
\end{tabular}


Tabela II. Média, máxima, mínima e desvio padrão da área total, área pastoril e número de cabeças do rebanho bovino de 2012 a 2014 nas unidades de produção (Average, maximum, minimum and standard deviation of the total area, pastoral area and number of heads of cattle from 2012 to 2014 in the production units).

\begin{tabular}{lcccc}
\hline & Média & Máxima & Mínima & Desvio Padrão \\
\hline Área total/ há & 1286 & 5517 & 86 & \pm 1339 \\
Área pastoril/ há & 430 & 2300 & 23 & 16 \\
Rebanho 2012/ cab & 852 & 3400 & 12 & \pm 392 \\
Rebanho 2013/ cab & 793 & 3500 & 20 & \pm 959 \\
Rebanho 2014/ cab & 855 & 3600 & \pm 893 \\
\hline
\end{tabular}

ficativo no número de animais do rebanho. Em relação ao desvio padrão, os valores encontrados foram de \pm 959 (2012), \pm 893 (2013) e \pm 970 (2014). Os altos valores podem ser explicados pela grande diferença entre a máxima e a mínima nos três anos (Tabela II).

Como se pode observar com a caracterização do elo de produção, os produtores entrevistados apresentam diferentes perfis quando comparados os tamanhos de propriedade e número de animais. No entanto, sendo todos eles pertencentes a mesma aliança mercadológica (APROCCIMA), trabalham por um objetivo comum e possuem os mesmos critérios de produção, referentes a idade, sexo, raça, tipo de alimentação e genética.

A APROCCIMA, em sua unidade de negócio carne bovina, caracteriza-se com a oferta de carne de animais jovens, com padrão racial baseado em raças britânicas, com rigoroso padrão de acabamento das carcaças, que é comercializada em pontos de venda associados (RIES et al., 2010).

\section{INDUSTRIALIZAÇÃO}

O elo de industrialização é representado por um único frigorífico, localizado na cidade de Farroupilha / RS. Se caracteriza por ser um prestador de serviços da aliança mercadológica APROCCIMA não tendo influência sobre as decisões da mesma.

Através de entrevista e aplicação de questionário diretamente com o dono da agroindústria, buscou-se caracterizar este elo da cadeia produtiva. O mesmo é do sexo masculino, 57 anos de idade, sendo que destes, 25 anos foram dedicados a esta atividade. Possui ensino superior completo e ocupa a função de diretor na empresa.

Com a coleta de informações, por meio de entrevista e questionário, pode-se constatar que a indústria frigorífica possui um abate médio de 120 animais/dia. A quantidade total de animais certificados abatidos por semana gira em torno de 500 , dividindo-se entre 300 machos e 200 fêmeas. Deste total é proveniente da APROCCIMA uma média de 50 animais, sendo 45 machos e 5 fêmeas, os demais são oriundos de outras localidades. O volume total de carne vendido por mês é de $40.000 \mathrm{~kg}$. Para atender a demanda da aliança, são realizados dois abates semanais no frigorífico.

Para que se haja ligação entre o elo da agroindústria com o elo produtor e posteriormente com o elo da distribuição, existem contratos de fidelidade. Em um primeiro momento com os produtores através de dois

Tabela III. Caracterização do elo de distribuição da aliança APROCCIMA, representada pelos varejos que comercializam a carne bovina (Characterization of distribution agents of alliance APROCCIMA, represented by retailers whose sell beef).

\begin{tabular}{|c|c|c|c|c|}
\hline & & Varejo & & \\
\hline & 1 & 2 & 3 & 4 \\
\hline Idade & 58 & 63 & 53 & 56 \\
\hline Tempo na atividade & 22 & 32 & 23 & 27 \\
\hline $\mathrm{N}^{\circ}$ clientes/ dia & $\mathrm{NF}^{*}$ & $\mathrm{NF}^{*}$ & 200 & 500 \\
\hline $\mathrm{N}^{\circ}$ clientes/ semana & $\mathrm{NF}^{*}$ & $\mathrm{NF}^{*}$ & 800 & 3500 \\
\hline Promoções & Não & Sim & Sim & Sim \\
\hline $\begin{array}{l}\text { Frequência promoções } \\
\text { vezes/semana }\end{array}$ & 0 & $\begin{array}{c}7 \\
\text { todos os dias }\end{array}$ & $\begin{array}{c}2 \\
\text { quarta/ sábado }\end{array}$ & $\begin{array}{c}2 \\
\text { sábado/domingo }\end{array}$ \\
\hline $\begin{array}{l}\text { Quantidade total carne } \\
\text { vendida mensal / kg }\end{array}$ & 8.000 & 10.000 & 3.200 & 10.000 \\
\hline Diferencial preços & Vendas à prazo & $20 \%$ & $5-10 \%$ & $10 \%$ \\
\hline $\begin{array}{l}\text { Contrato fidelidade } \\
\text { APROCCIMA }\end{array}$ & $\begin{array}{l}\text { Sim } \\
\text { Quantidade } \\
\text { Período }\end{array}$ & $\begin{array}{l}\text { Sim } \\
\text { Quantidade } \\
\text { Período }\end{array}$ & $\begin{array}{l}\text { Sim } \\
\text { Período }\end{array}$ & $\begin{array}{l}\text { Sim } \\
\text { Período }\end{array}$ \\
\hline Principais cortes vendidos & $\mathrm{NF}^{*}$ & Carne $2^{\circ}$ & $\begin{array}{l}\text { Traseiro, alcatra, maminha, costela, } \\
\text { ripa, coxão mole }\end{array}$ & $\begin{array}{l}\text { Alcatra, picanha, coxão de } \\
\text { dentro, ripa da costela }\end{array}$ \\
\hline
\end{tabular}


pré-requisitos: número de cabeças e período e em um segundo momento entre agroindústria e varejo: quilos e período.

No quesito de limite de abate, o diretor da empresa alegou ser o comércio de carne restrito o motivo que leva a essa limitação. Este pode ser um ponto importante para ser trabalhado futuramente.

Em relação a diferencial de preços na compra do animal vivo e venda da carcaça, há uma diferença de $10 \%$ em ambos os sexos em relação ao mercado. O prazo médio de pagamento da agroindústria com produtor é de 10 dias e varejo com agroindústria 30 dias em média.

Em função da aliança, houve aumento de venda de carne e aumento do número de estabelecimentos de varejo, totalizando hoje quatro unidades de venda.

\section{DISTRIBUIÇÃO}

Quando se trata do elo de distribuição da aliança mercadológica em estudo, o mesmo é representado por quatro varejos, distribuídos em duas cidades: Antônio Prado e Caxias do Sul. Para a caracterização da amostra, os varejos foram numerados, sendo 1 e 2 situados na cidade de Caxias do Sul e 3 e 4 em Antônio Prado.

A coleta de informações se deu através de aplicação de questionário e entrevista direta com os respectivos donos de cada varejo, onde se buscou informações que pudessem caracterizar o elo de distribuição.

Na Tabela III, observa-se que a faixa etária dos donos dos estabelecimentos está entre 53 e 63 anos de idade. O tempo na atividade tem o mínimo de 22 e o máximo de 32 anos. Estes dados nos indicam um alto grau de experiência em anos por parte dos donos neste segmento, apresentando uma média de 26 anos de atividade.

No que se refere à proporção mensal de carne vendida em quilos, varejos 2 e 4 apresentaram a mesma quantidade em vendas, $10.000 \mathrm{~kg}$ cada um. Apesar de estarem localizados em cidades distintas, os dois mercados mencionados se assemelham em aspectos como estrutura física, público alvo e método de funcio- namento, o que pode vir a justificar este dado (Tabela III).

No caso do varejo 1, a disponibilidade de produtos diferenciados (não somente a carne bovina APROCCIMA, que também é trabalhada e vendida de maneira diferenciada), o nível econômico dos consumidores frequentadores e o atendimento ao cliente lhe desenha em um modelo mais próximo a uma boutique ou casa de carnes do que a um mercado comum.

Em relação ao elo de distribuição, cabe ressaltar que a carne bovina vendida em todos os quatro mercados é exclusivamente oriunda da aliança. A APROCCIMA vende e entrega aos varejos a carcaça inteira. O produto no varejo é vendido in natura, nos balcões dos açougues. A apresentação final do produto cárneo que chega até o cliente, diferenciação e aspecto do produto para venda, atendimento ao cliente, ponto de venda entre outros fatores é de responsabilidade do próprio varejo. Estes fatores juntamente com a metodologia de trabalho de cada estabelecimento é o que acaba diferenciando a venda do produto.

\section{CONSUMIDOR}

Para a caracterização do perfil de consumidores, realizada por meio de questionário, foram utilizadas as variáveis: gênero e idade (Tabela IV). Na segunda etapa, para realização dos testes de aceitação, contouse com a colaboração de 114 participantes.

A amostra do elo consumidor deste estudo se caracteriza por apresentar potenciais consumidores para a carne bovina da marca APROCCIMA, visto que, com os testes de aceitação puderam ter um primeiro contato com o produto, já que ainda não está sendo comercializado na região.

Observa-se que os consumidores do sexo masculino foram mais representativos, sendo $61 \%$ do total da amostra. Quanto à idade, 41\% dos entrevistados são da faixa etária de até 25 anos, 28\% de 41 a 60 anos, 26\% de 26 a 40 . A alta representatividade do público jovem reflete uma pesquisa feita em uma feira agropecuária, caracterizada por um público de todas as idades desde menores de um ano até idosos que visitam a feira

Tabela IV. Caracterização da amostra de consumidores de teste de aceitação conforme o gênero e idade (Sample consumer of acceptation test characterization according gender and age).

\begin{tabular}{|c|c|c|c|}
\hline \multirow[t]{2}{*}{ Característica } & \multirow[t]{2}{*}{ Variável } & \multicolumn{2}{|c|}{ Consumidores } \\
\hline & & Número & Frequência \\
\hline \multirow[t]{2}{*}{ Gênero } & Masculino & 61 & $54 \%$ \\
\hline & Feminino & 53 & $46 \%$ \\
\hline \multirow[t]{5}{*}{ Idade } & Até 25 anos (jovens) & 47 & $41 \%$ \\
\hline & De 26 a 40 anos (adultos) & 29 & $26 \%$ \\
\hline & De 41 a 60 anos (maduros) & 32 & $28 \%$ \\
\hline & Mais de 60 anos (idosos) & 5 & $4 \%$ \\
\hline & Não informado & 1 & $1 \%$ \\
\hline Cidade & Santa Maria & 114 & $100 \%$ \\
\hline
\end{tabular}


em um programa familiar com grande quantidade de adolescentes e crianças.

\section{TESTES DE ACEITAÇÃO}

Na primeira questão do teste de aceitação, buscouse conhecer a posição que melhor reflete o julgamento do consumidor em relação à carne APROCCIMA (Figura 1). Observa-se que a mesma teve uma boa aceitabilidade, visto que $92 \%$ dos entrevistados marcaram entre as opções: "gostei muito" (46\%) e "gostei" (46\%).

Na Figura 2 estão expostas as respostas quanto à atitude em relação à compra do produto. Mais da metade dos respondentes (51\%) indicou a opção de "certamente compraria", seguida de "provavelmente compraria" (40\%). Apenas 2\% entre os entrevistados marcaram a opção "certamente não compraria", indicando uma porcentagem mínima de rejeição ao produto.

A APROCCIMA busca a valorização dos produtos oriundos dos Campos de Cima da Serra por meio da oferta de qualidade diferenciada. Para atender esta diferenciação, existe uma série de critérios relacionados a variáveis como raça, sistemas de produção, idade de abate que devem ser respeitados por todos os seus elos, com a finalidade de um produto final de qualidade com características que atendam as demandas e necessidades dos seus consumidores.

Através do teste de aceitação nota-se que houve uma boa aceitabilidade por parte dos consumidores em relação ao produto oferecido para degustação. Com a aplicação da terceira e última questão do teste de aceitação, representada através da Figura 3, buscou-se saber a opinião dos consumidores quando compararam o produto em estudo oferecido para degustação com as carnes bovinas que já estavam habituados a consumir. Nota-se que $47 \%$ julgaram a carne bovina APROCCIMA como sendo igual a produtos já consumidos por eles; 34 \% melhor; $11 \%$ muito melhor e apenas $7 \%$ como sendo pior.

Os resultados encontrados no teste de aceitação mostram que a carne bovina APROCCIMA teve uma alta aceitabilidade no público da cidade de Santa Maria. Estes resultados são bastante positivos, visto que, indicam um mercado futuro em potencial para os

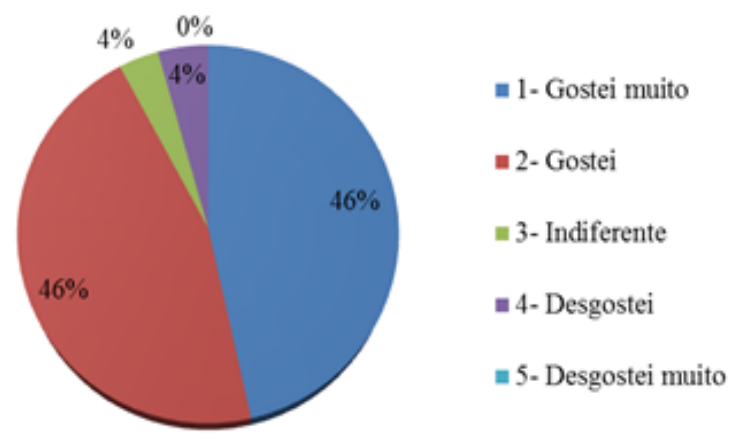

Figura 1. Posição que melhor reflete o julgamento do consumidor em relação à carne (Position that best reflects the consumer's judgment for meat).

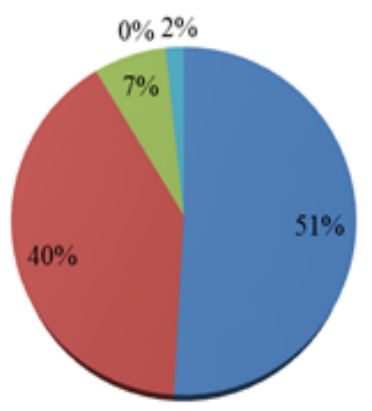

$$
\begin{aligned}
& \text { 1- Certamente } \\
& \text { compraria } \\
& \text { = 2- Provavelmente } \\
& \text { compraria } \\
& \text { =3-Tenho dúvidas se } \\
& \text { compraria } \\
& \text { = 4- Provavelmente não } \\
& \text { compraria } \\
& \text { = 5- Certamente não } \\
& \text { compraria }
\end{aligned}
$$

Figura 2. Atitude em relação à compra do produto. (Attitude towards the purchase of the product).

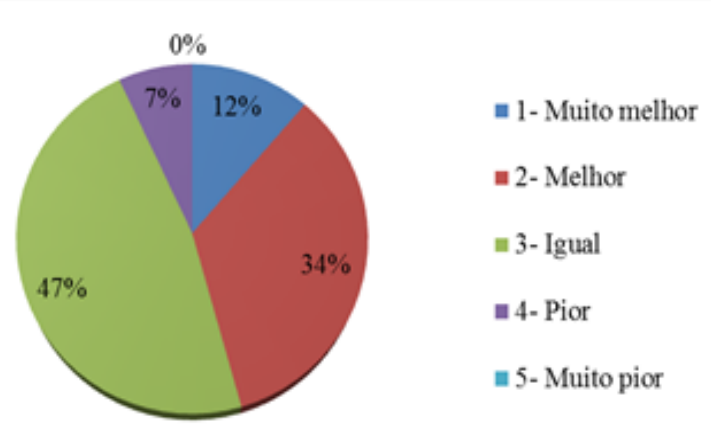

Figura 3. Comparação em relação às outras carnes que os consumidores costumam degustar. (Comparison in relation to other meats that consumers often enjoy).

produtos da aliança mercadológica em estudo. Vale salientar, que os produtos cárneos da APROCCIMA estão disponíveis para venda apenas nas cidades de Antônio Prado e Caxias do Sul. O teste de aceitação, neste caso, pode ser entendido como uma importante ferramenta na busca por novos mercados consumidores, abrangendo cidades que se caracterizem por possuírem potencial para o consumo destes produtos, dissipando assim a marca.

\section{CONCLUSÃO}

1. Por meio desta pesquisa se obteve a caracterização da cadeia produtiva APROCCIMA, que se organiza em forma de aliança mercadológica, por meio da identificação dos seus elos e a compreensão da sua estrutura e funcionamento.

2.O produto cárneo da marca APROCCIMA, teve aceitabilidade no que se refere ao julgamento do consumidor em relação ao produto e intenção de compra positiva.

3. A análise do perfil e comportamento dos consumidores das carnes APROCCIMA servem de base para a identificação de preferências e potenciais de consumo. 
4. O presente estudo servirá de ferramenta da cadeia de produção da APROCCIMA para desenvolver estratégias futuras para possíveis mercados.

\section{BIBLIOGRAFIA}

Batalha, M.O. 2009. Gestão agroindustrial. 3 ed. São Paulo: Atlas.

Ferreira, G.C. e Padula, A.D. 1998. Estrutura produtiva e competitividade da cadeia da carne bovina no Rio Grande do Sul. Encontro Anual da ANPAD, v. 22

Lima, M.P. e Anjos, M.A.D. 2017. Evolução do comércio varejista de carnes e a importância do atendimento ao cliente: um estudo de caso na empresa açougue do Guilherme. Revista Getec; 6: 59-73.

Malafaia, G.C.; Blume, R.; Maciel, A.C. e Camargo, M.E. 2010. Rede de produtores rurais e gestão dos recursos. Revista Pretexto; 11: 41-54.

Malhotra, N. 2006. Pesquisa de marketing: uma orientação aplicada. 4 ed. Porto Alegre: Bookman, $101 \mathrm{p}$.

Minim, V.P.R. 2012.Análise sensorial: estudos com consumidores. 2 ed. Viçosa: Editora UFV, 66p.
Neumann, M. e Barcellos, J.O.J. 2006. Estratégias de coordenação: princípios para a formação de alianças mercadológicas: "Alianças que deram certo". In: Jornada técnica em sistemas de produção de bovinos de corte e cadeia produtiva: tecnologia, gestão e mercado, 1, 2006, Porto Alegre/RS. Anais...Porto Alegre/RS: Universidade Federal do Rio Grande do Sul.

Pineda, N.R. e Rocha, J.C.M. de C. 2002. Estratégias de marketing e alianças mercadológicas na cadeia produtiva da carne bovina. In: Simpósio de produção de gado de corte, 3, 2002, Viçosa/MG. Anais... Viçosa/MG: Universidade Federal de Viçosa.

Regmi, A. and Gehlthar, M. 2001. Consumer preferences and concerns shape global food trade. Food Review; 24: 2-8.

Vieira, S. e Hossne, W. S. 2015. Metodologia científica: para a área de saúde. Elsevier Brasil.

Wood Junior, T. and Zuffo, P.K. 1997. Supply chain management. Revista de Administração de Empresas; 38: 55- 63. 